ISSN (Print): 2709-9636 | ISSN (Online): 2709-9644

Volume 2, 2021(Issue III, July to September)

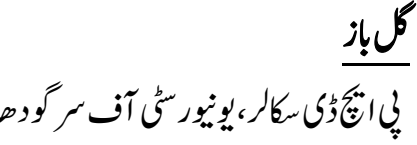

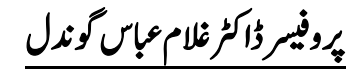

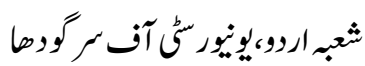

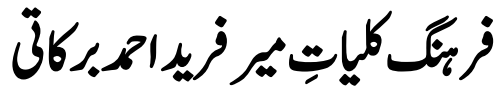

Gul Baz

PhD Scholar, University of Sargodha.

Prof. Dr. Ghulam Abbas Gondal

Department of Urdu, University of Sargodha.

\section{Farhang Kuliyat i Mir Farid Ahmad Barkati}

"Farhang i Kuliyat i Meer" prepared by Farid Ahmad Barakati is a major work on the poetry of Meer Taqi Meer in genre of glossary. In contains most of word, compounds, idioms and figurative points of verses. He writes vocabulary meanings, poetic meanings and sometimes central idea of verse. He points out the words not used now a day. He also mentions the words and idiomatic expression: generally not opted for poetic expression but Meer arranged them delicately. It is a major work and most important one among the glossaries of classical Urdu poetry.

Key Words: Meer, Barakati, Farhang, Expressions, Glossary, Poetry, Meaning, Classical, Idiomatic.

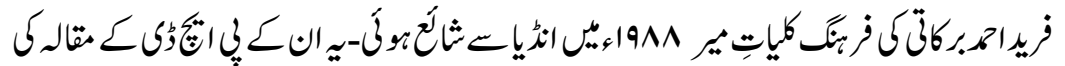

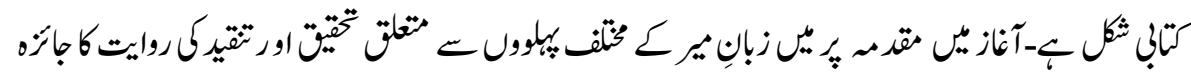

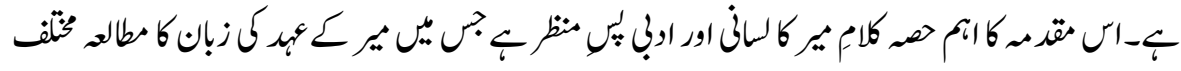

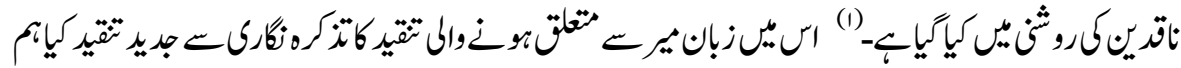

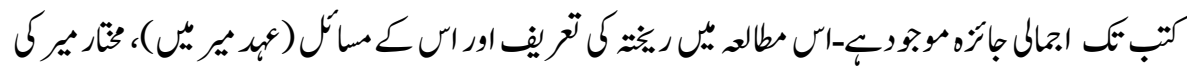

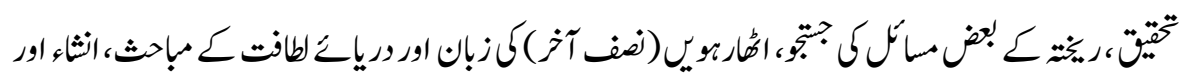

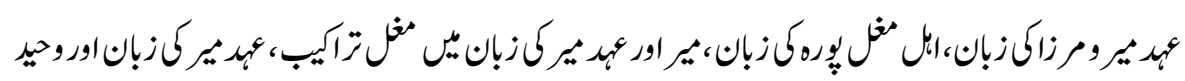


ISSN (Print): 2709-9636 | ISSN (Online): 2709-9644

Volume 2, 2021(Issue III, July to September)

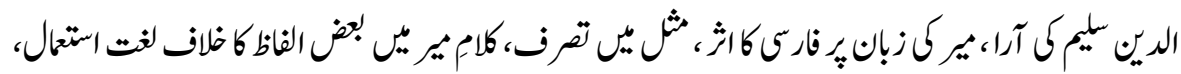

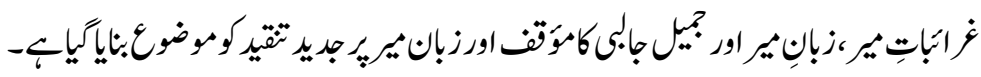

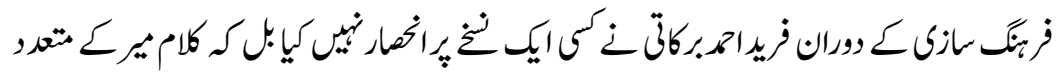

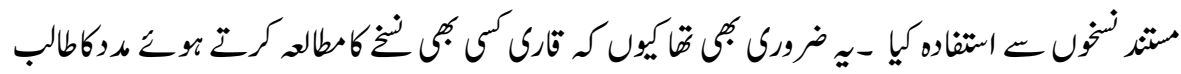

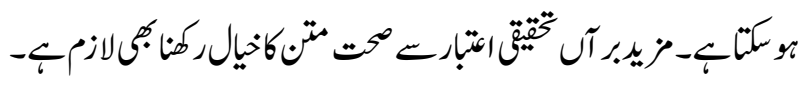

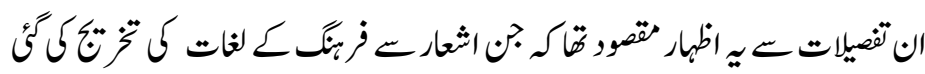

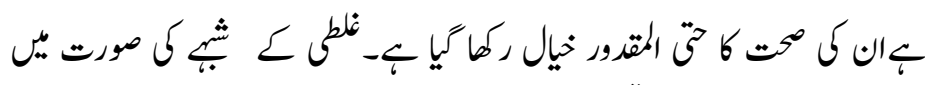
(r)

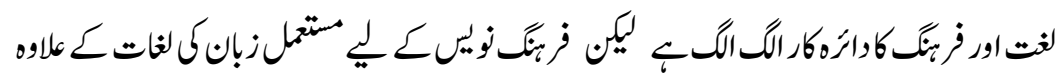

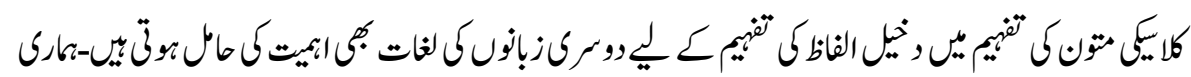

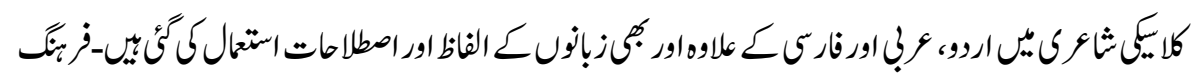

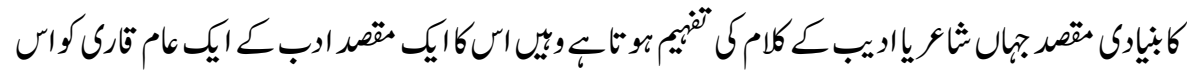

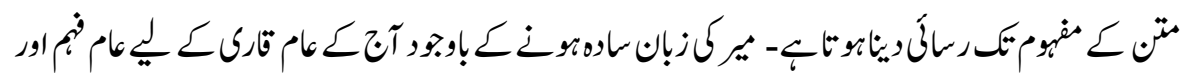

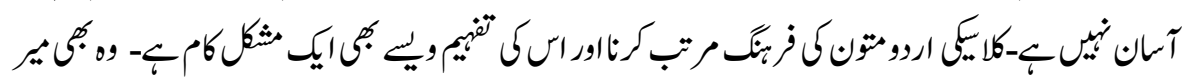

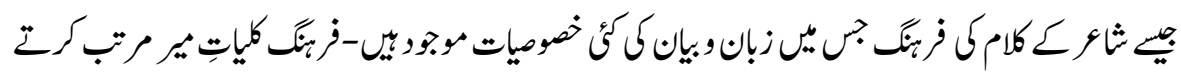

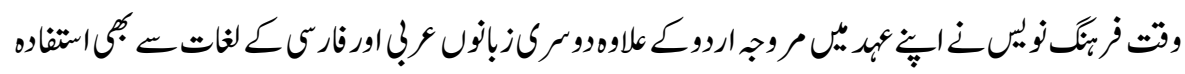

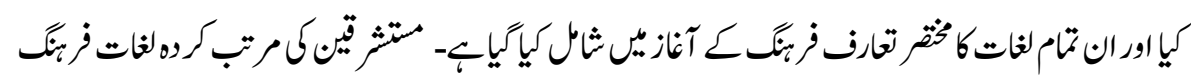

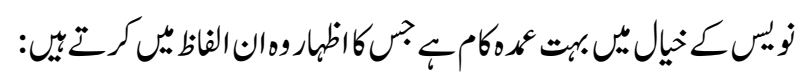

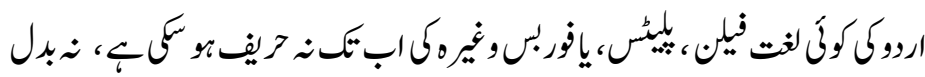

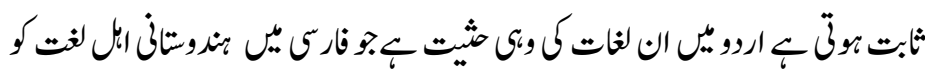

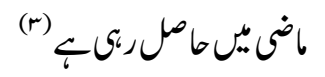

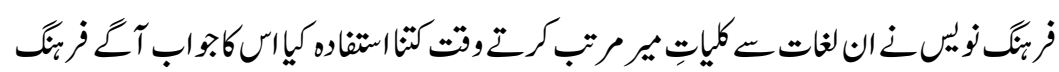

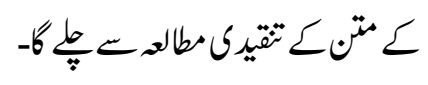


ISSN (Print): 2709-9636 | ISSN (Online): 2709-9644

Volume 2, 2021(Issue III, July to September)

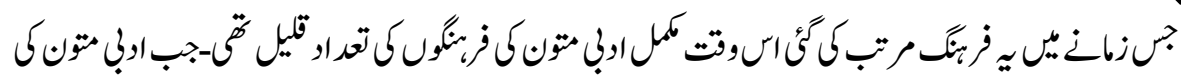

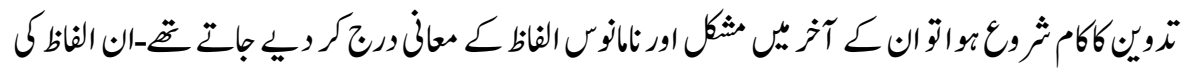

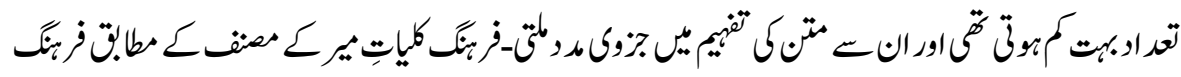

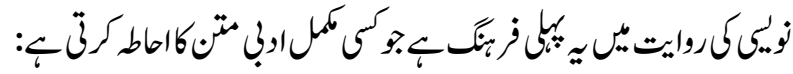

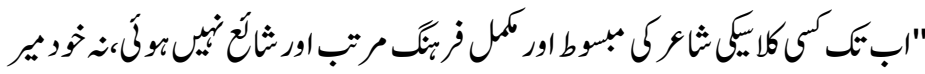

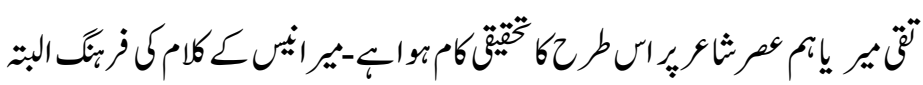

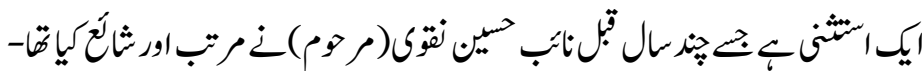

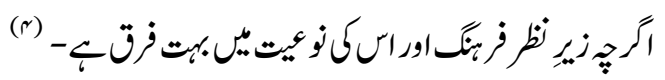

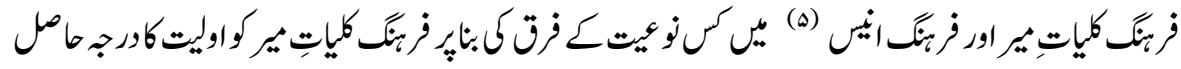

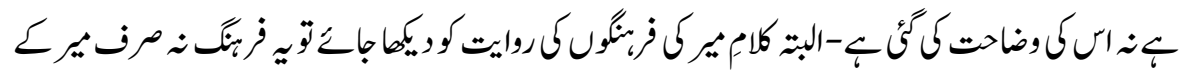

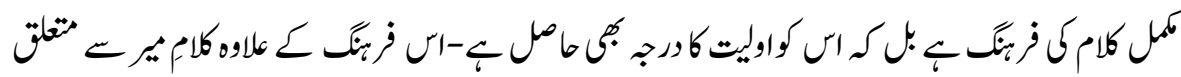

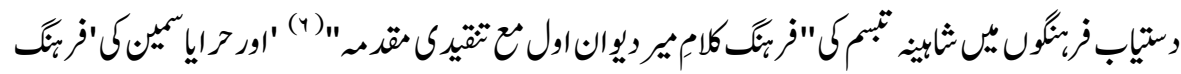

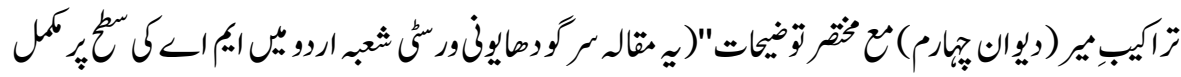

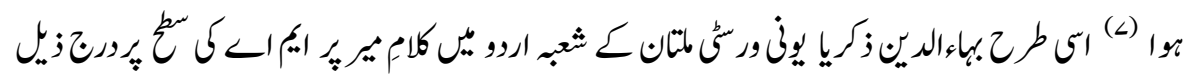

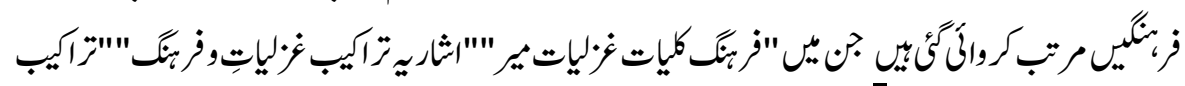

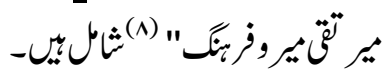

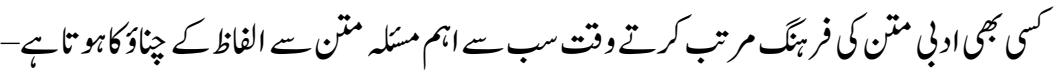

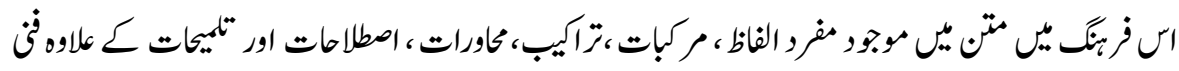

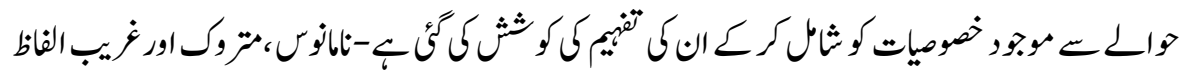

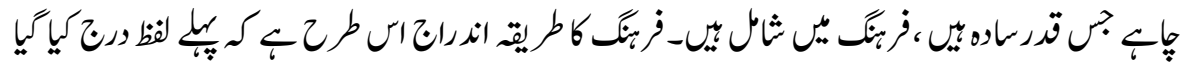

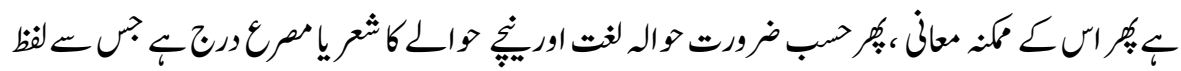

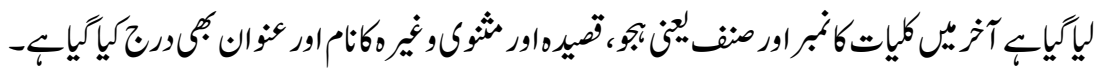


ISSN (Print): 2709-9636 | ISSN (Online): 2709-9644

Volume 2, 2021(Issue III, July to September)

انز تميقيق مجلد

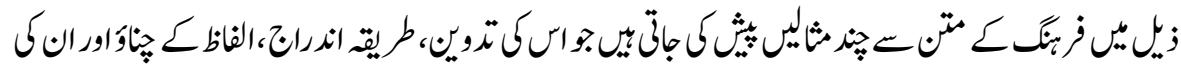

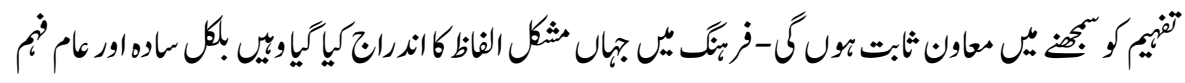

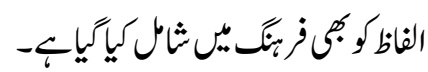

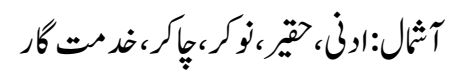

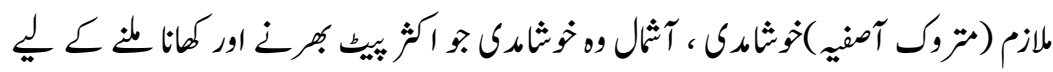

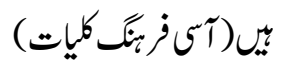

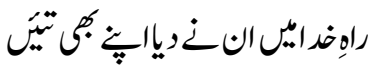

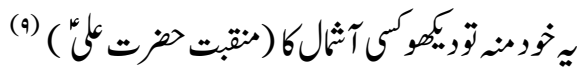

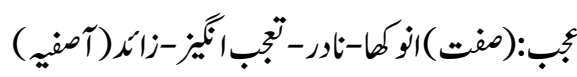

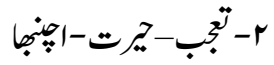

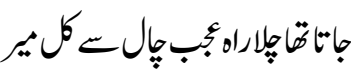

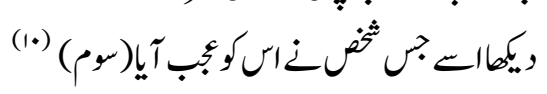

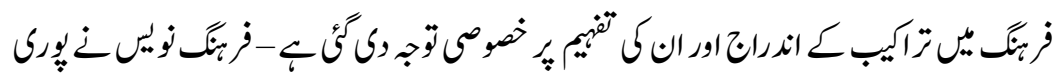

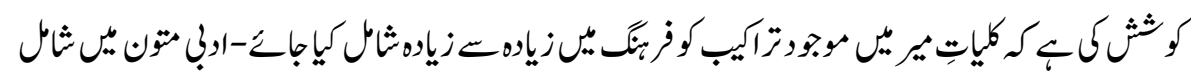

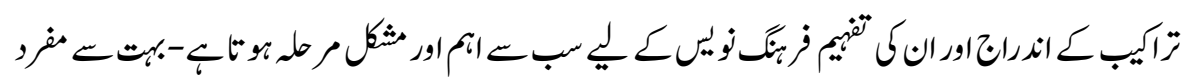

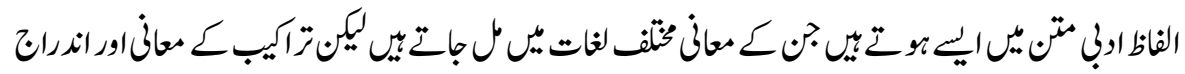

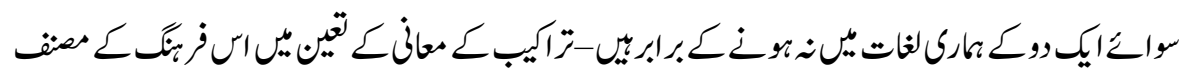

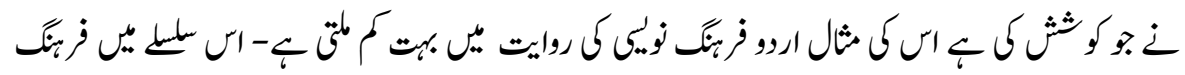

$$
\text { كمثنفر تمرازيبك: }
$$

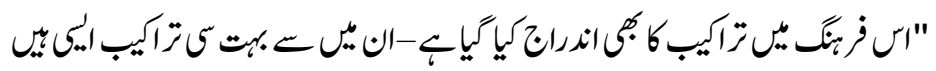

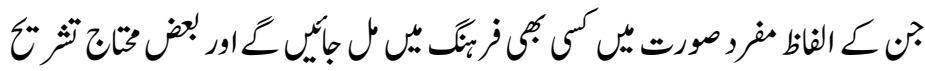

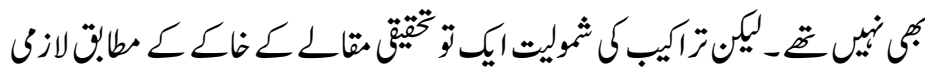

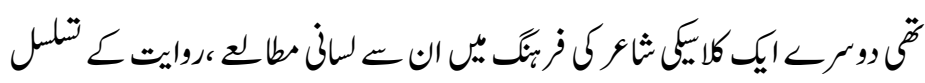


ISSN (Print): 2709-9636 | ISSN (Online): 2709-9644

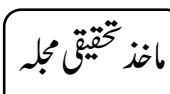

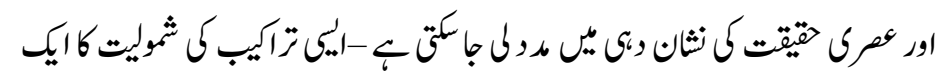

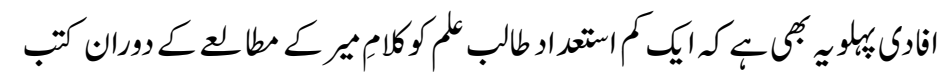

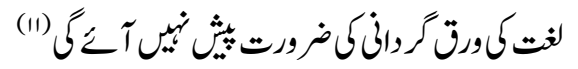

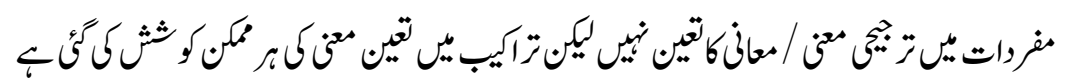

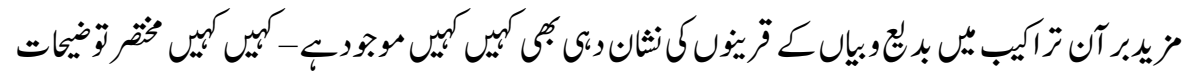

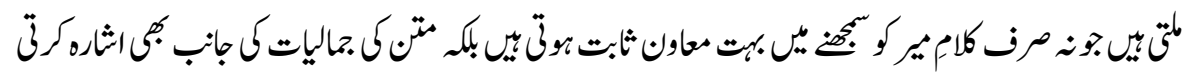

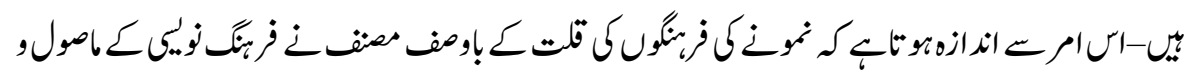

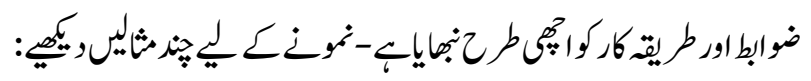

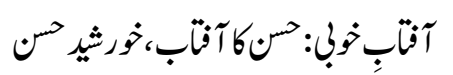

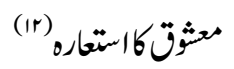

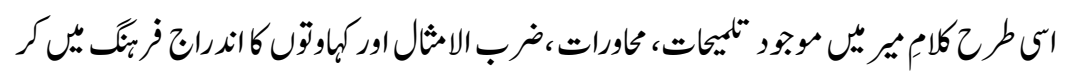

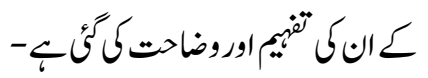

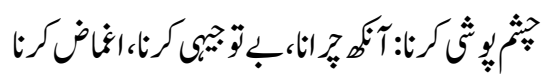

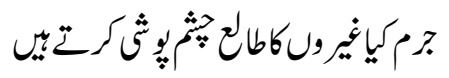

(r)

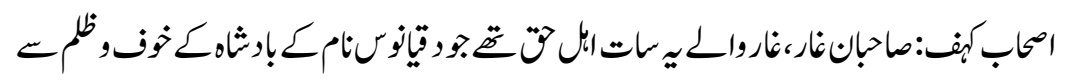

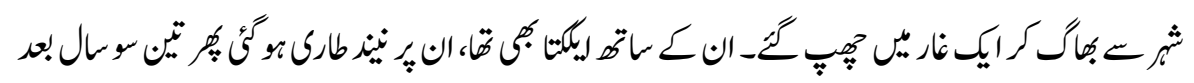

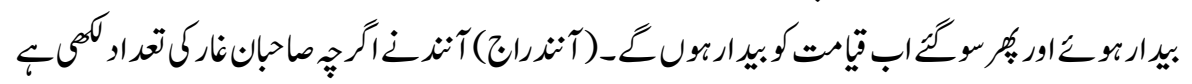

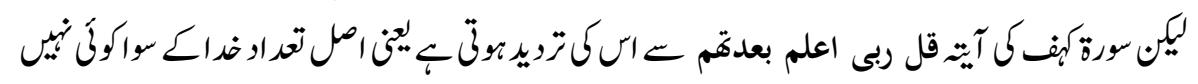

بإب

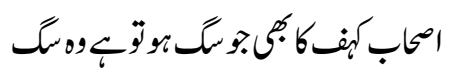

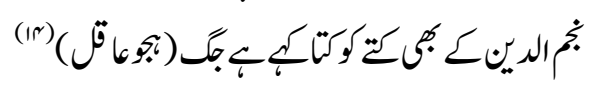

IrL 
ISSN (Print): 2709-9636 | ISSN (Online): 2709-9644

Volume 2, 2021(Issue III, July to September)

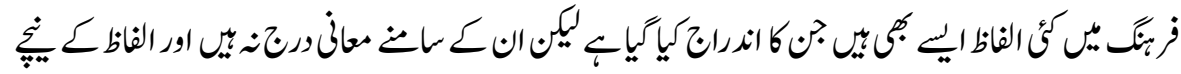

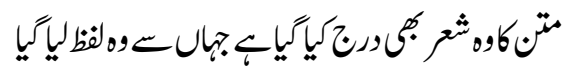

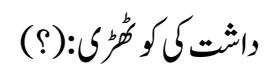

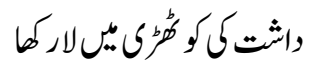

$$
\text { (1) }
$$

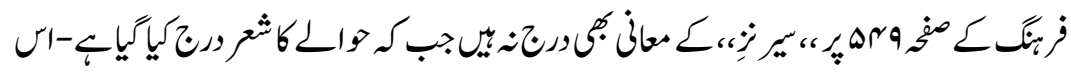

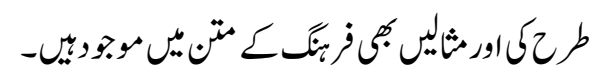

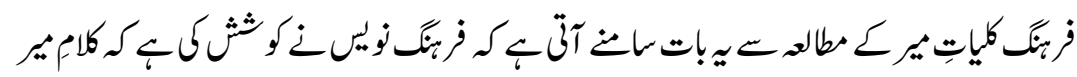

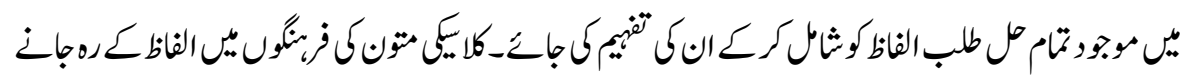

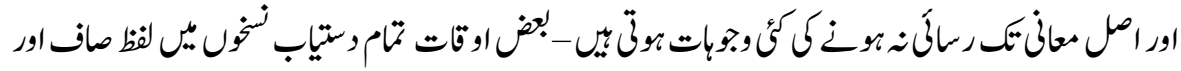

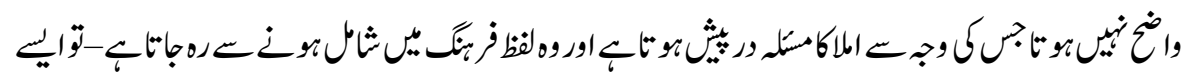

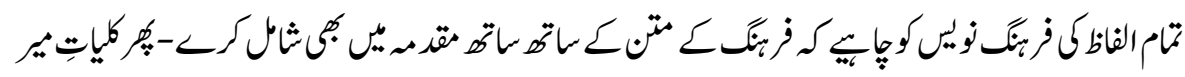

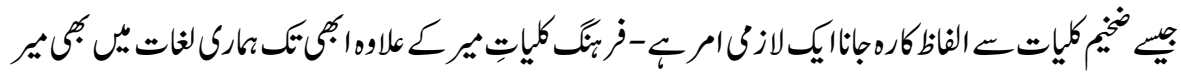

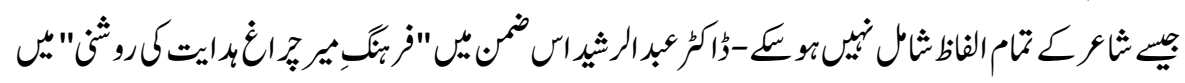

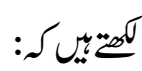

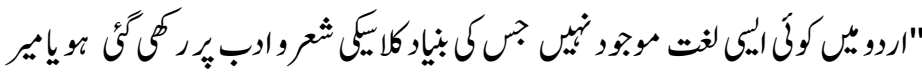

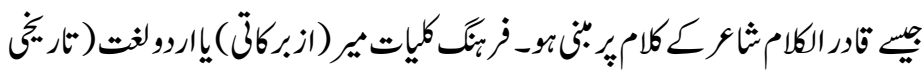

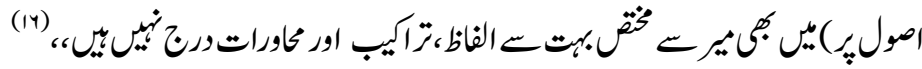

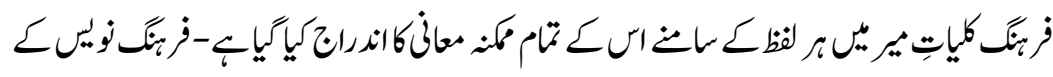

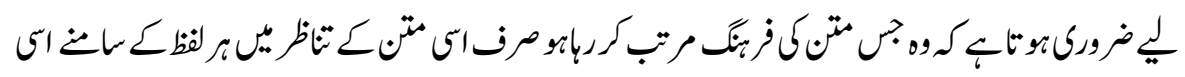

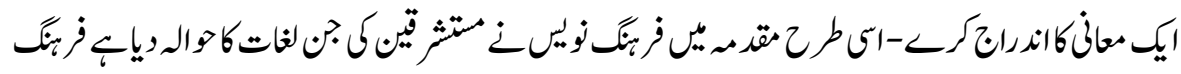

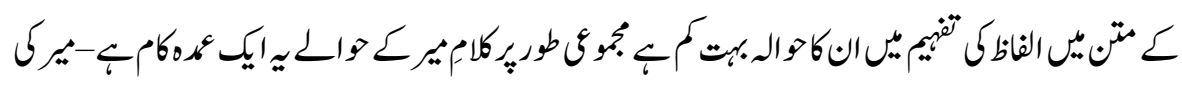

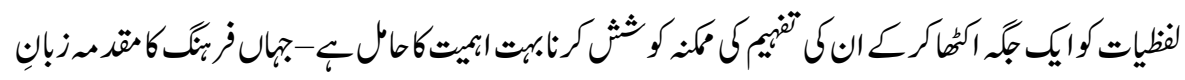


ISSN (Print): 2709-9636 | ISSN (Online): 2709-9644

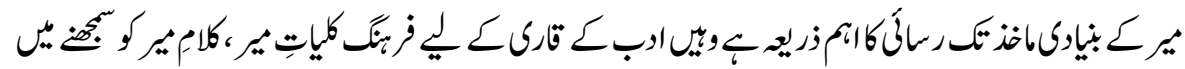

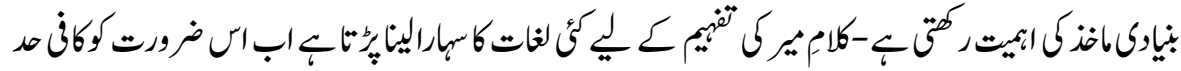

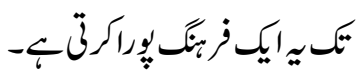
والرجات

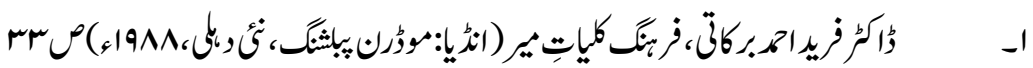

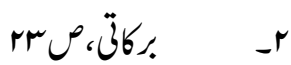
r

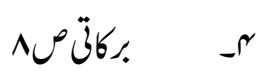

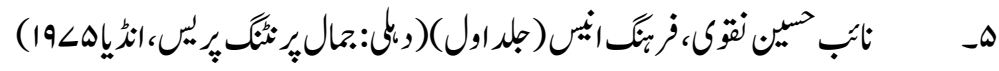

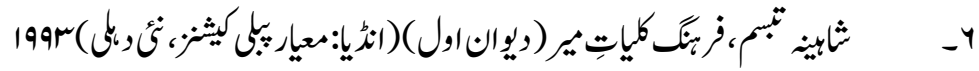

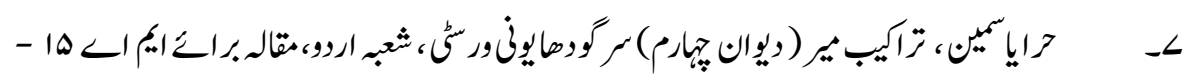
cro ir

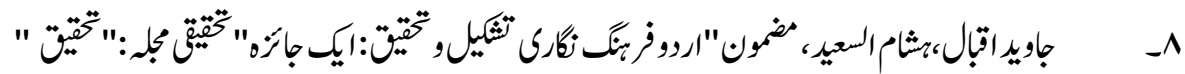

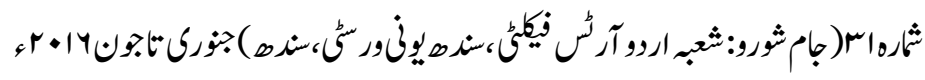

ه

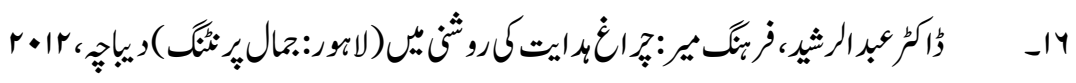

